Perspective

J Prev Med Public Health 2020;53:228-232 • https://doi.org/10.3961/jpmph.20.166

pISSN 1975-8375 elSSN 2233-4521
Journal of

Preventive Medicine

\& Public Health

\title{
The Pandemic League of COVID-19: Korea Versus the United States, With Lessons for the Entire World
}

\author{
Alwin Issac', Shine Stephen', Jaison Jacob', Vijay VR', Rakesh Vadakkethil Radhakrishnan', Nadiya Krishnan', \\ Manju Dhandapani ${ }^{2}$ \\ ${ }^{1}$ College of Nursing, All India Institute of Medical Sciences (AIIMS), Bhubaneswar, India; ${ }^{2}$ Post-Graduate Institute of Medical Education and Research \\ (PGIMER), Chandigarh, India
}

Coronavirus disease 2019 (COVID-19) is inflicting a brutal blow on humankind, and no corner of the world has been exempted from its wrath. This study analyzes the chief control measures and the distinctive features of the responses implemented by Korea and the United States to contain COVID-19 with the goal of extracting lessons that can be applied globally. Even though both nations reported their index cases on the same day, Korea succeeded in flattening the curve, with 10752 cases as of April 28, 2020, whereas the outbreak skyrocketed in the United States, which had more than 1 million cases at the same time. The prudent and timely execution of control strategies enabled Korea to tame the spread of the virus, whereas the United States paid a major price for its delay, although it is too early to render a conclusive verdict. Information pertaining to the number of people infected with the virus and measures instituted by the government to control the spread of COVID-19 was retrieved from the United States Centers for Disease Control and Prevention and the Korea Centers for Disease Control and Prevention websites and press releases. Drawing lessons from both nations, it is evident that the resolution to the COVID-19 pandemic lies in the prudent usage of available resources, proactive strategic planning, public participation, transparency in information sharing, abiding by the regulations that are put into place, and how well the plan of action is implemented.

Key words: Coronavirus, COVID-19, Pandemic, Containment, Quarantine

It took a mere 2 and half months for the novel coronavirus-now known as severe acute respiratory syndrome coronavirus 2 (SARS-CoV-2) - to emerge from the city of Wuhan in China and to spread its tentacles across the globe, spewing disease and death in its trail and becoming a pandemic. As of April 28, 2020, nearly 3 million cases of coronavirus disease 2019 (COVID-19) have been confirmed globally, with a death

Received: April 30, 2020 Accepted: May 23, 2020

Corresponding author: Shine Stephen, MSN

College of Nursing, All India Institute of Medical Sciences (AIIMS),

Sijua, Post-Dumuduma, Patrapada, Bhubaneswar 751019, India

E-mail: shinestephentn@gmail.com

This is an Open Access article distributed under the terms of the Creative Commons Attribution Non-Commercial License (https://creativecommons.org/licenses/by$\mathrm{nc} / 4.0 /$ ) which permits unrestricted non-commercial use, distribution, and reproduction in any medium, provided the original work is properly cited. toll of 211792 [1].

The United States (US) tops the Global Health Security (GHS) index, with an overall score of 83.5 out of 100. The GHS index compares the health security-related capabilities of 195 countries using 6 different indicators: prevention, health system, detection and reporting, compliance with international norms, rapid response, and risk environment. Korea is in ninth place, with a score of 70.2. However, a meticulous evaluation of the containment strategies implemented for COVID-19 reveals that Korea managed the pandemic very effectively. For diseases spread through contact, population density is a highly relevant consideration. Despite its population density of 530 people $/ \mathrm{km}^{2}$, Korea succeeded in limiting its caseload to 10752 (Figure 1) with 244 deaths [2], whereas in the US, with a population density of 36 people $/ \mathrm{km}^{2}$, the caseload escalated to 1010507 


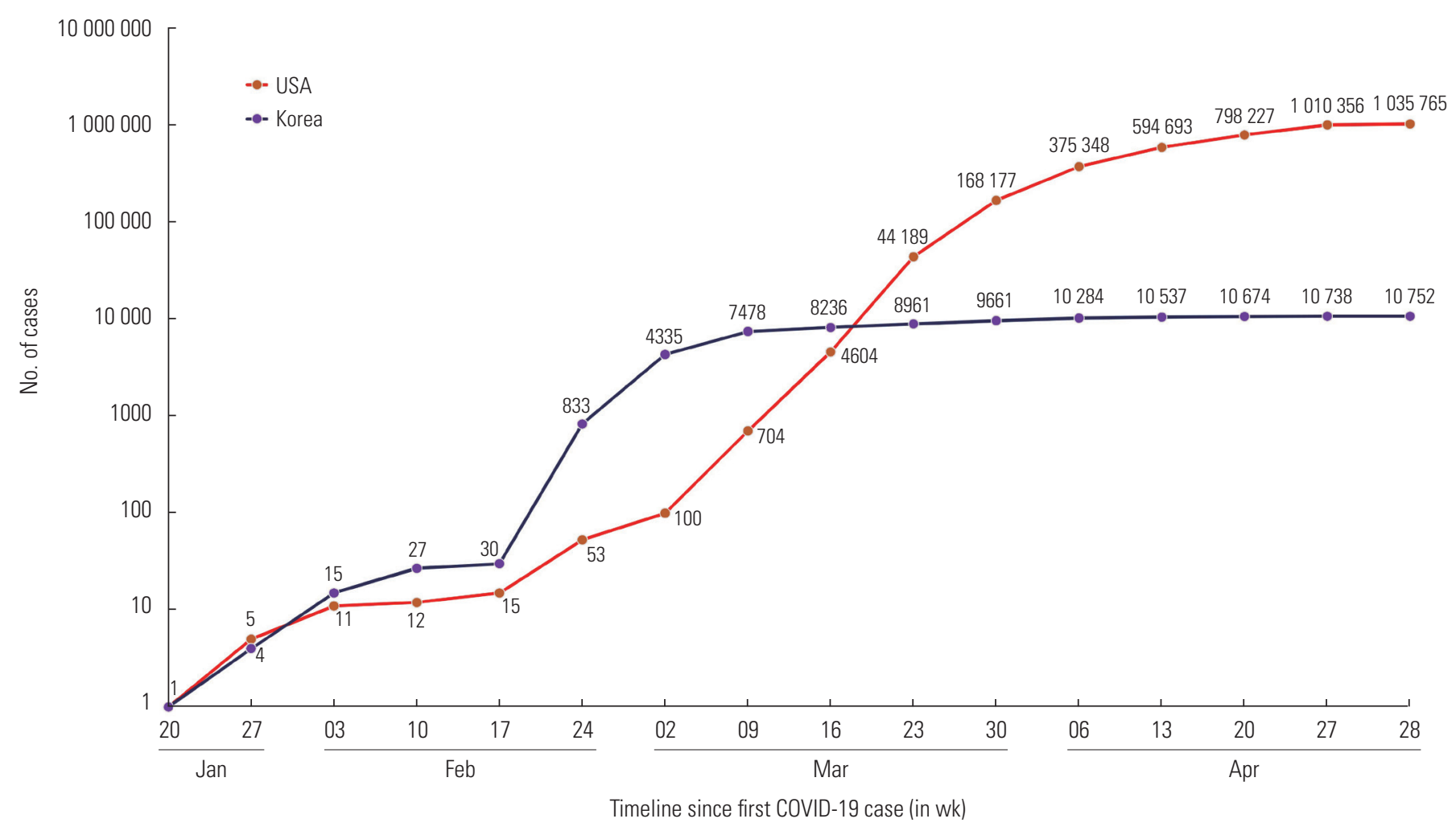

Figure 1. Timeline comparing the number of coronavirus disease 2019 (COVID-19) cases in the United States and Korea.

(Figure 1) with 56803 deaths (as of April 28, 2020) [1]. According to the Human Development Index, the US is ranked 15th, whereas Korea is ranked 22nd [3]. Scientific community across the globe is curious to understand how Korea controlled this disease so successfully, although both nations reported their index cases on the same day (January 20,2020).

The authors conducted a thorough literature review to determine the major measures taken by these 2 nations, with a major emphasis on their preparedness, imposition time, and rigor in enforcement measures. These findings shed light on key learning points for how to address any disease outbreak, and thereby aid in policy development and preparedness steps for other nations to follow.

Upon the initial report of COVID-19, the Korean Centers for Disease Control and Prevention (KCDC) set up a task force and mapped out the available resources [4]. An all-governmental approach was taken to establish the task force, including all ministries, regional governments, and city governments, which made coordination hassle-free. Even before Korea recorded its first case, the Korean government initiated a screening program and the KCDC sent a task force to Wuhan to study the outbreak. Their extensive testing enabled them to implement early iso- lation and quarantine and minimized the chance for community transmission. As soon as the genetic sequence of the SARSCoV- 2 was released by China, Korean health authorities developed and stocked testing kits. Production expanded swiftly through a public-private partnership after the country reported its first COVID-19 case.

With the index case, key epidemiological investigative tools were swiftly employed, including case investigation and management, contact tracing through route mapping, evaluation of risk exposure, classification of contacts (close and casual contacts) and contact management (through compulsory testing and quarantine). The nation's leadership in digital technology was well utilized to overcome shortcomings in contact tracing, and technology such as global positioning systems (GPS), card transaction logs, and closed-circuit televisions were employed to strengthen contact tracing [5]. Drive-through screening centers were set up for safe and efficient screening to prevent a massive community outbreak. This strategy was later adopted by many developed nations [6]. Furthermore, the mobile application "Corona-100m" was deployed, which alerted people who came within 100 meters from places where confirmed cases had been. The steep rise in the caseload that started on 
February 19, 2020 through case \#31, who attended a mass gathering in a church, spurred the Korean administration to intensify containment, with a travel ban to 15 countries, a partial lockdown in Daegu (the city most strongly affected by the outbreak city), shutdown of educational institutions, and a further surge in testing [7].

More importantly, asymptomatic people were tested irrespective of their contacts with proven cases, which proved to be a crucial move for curtailing community spread. Korea set a new landmark by testing 1 out of every 100 of its citizens, and as of April 28, 2020 almost 608514 tests have been performed [2]. People with a history of contacts with proven cases were strictly quarantined, with digital monitoring of the quarantine. Violators were punished with fines and imprisonment. Patients were categorized by risk and only high-risk patients were hospitalized. People voluntarily refrained from venturing into public places and self-imposed social distancing measures were followed. There was also widespread use of masks by the public.

The government's transparency in information-sharing regarding key features of the outbreak and the standard procedures to follow aided in combatting the spread of rumors related to the outbreak. Notably, Korea is one of the few nations that have sound standard operating procedures to be followed for containing epidemics.

Owing to its slow start in COVID-19 testing, the US lost pivotal time during the early weeks of the disease surge. Although the US developed its own testing approach, it was found that many tests were inaccurate and defective [8]. On January 31, 2020, a public health emergency was declared and foreign nationals who had travelled through China, Iran, and European countries in the past fortnight were barred entry. US citizens returning home through those regions had to go through a health screening and were quarantined for 14 days. A nationwide lockdown was not enacted, and drive-through testing centers were only established by March 13, 2020.

The decentralized health care system in the US made it difficult to implement rigorous health care initiatives, and notable disparities among states in policy designs and enforcement of containment measures were evident. It took time for the federal government to put in place proper directions for the 50 states, during which time the country combatted COVID-19 without a streamlined national plan. Contradictory statements from administrators triggered chaos, and the public was not informed about the criticality of the situation in advance. Strin-

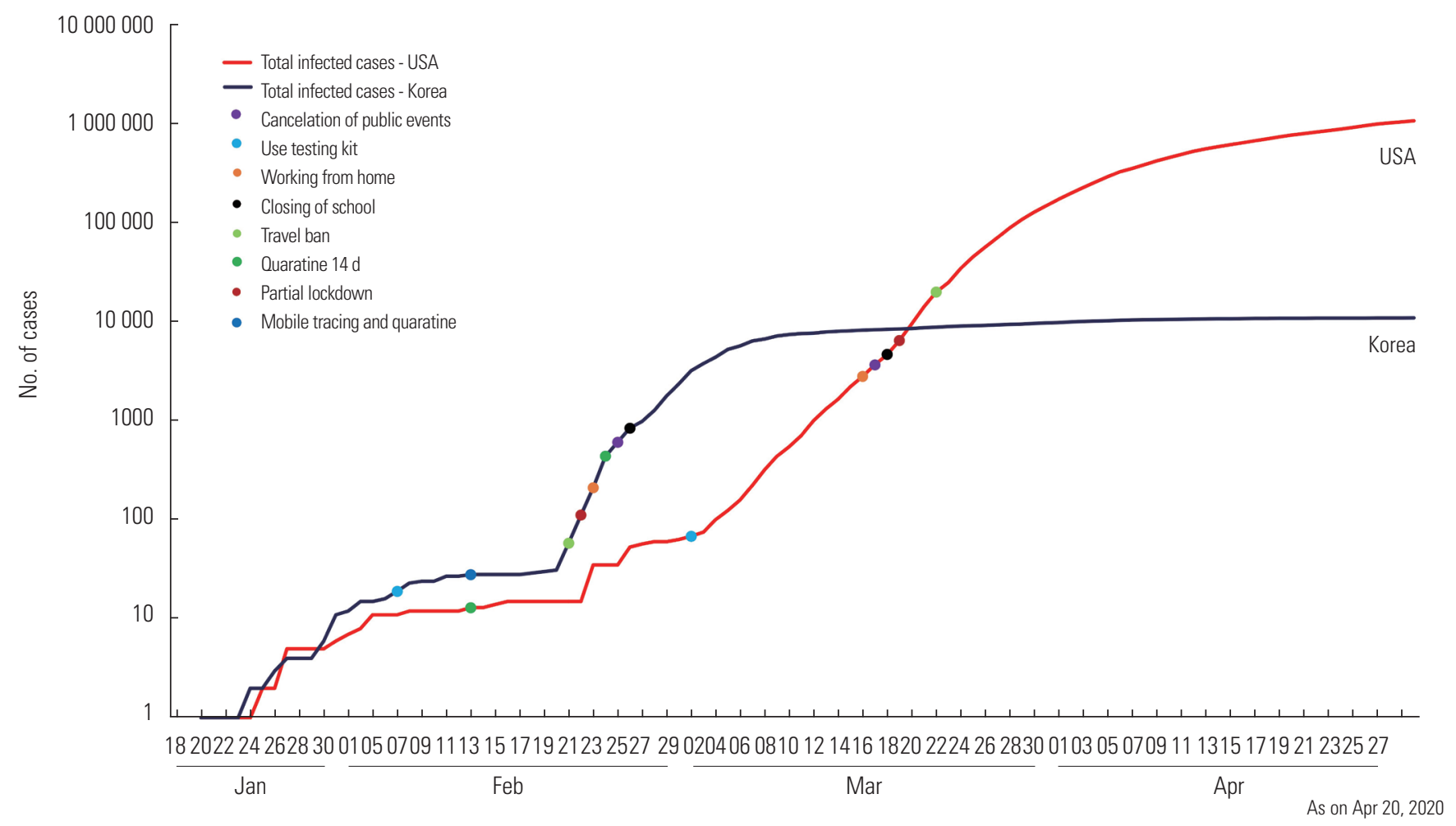

Figure 2. Timeline comparing containment measures taken by the United States and Korea against coronavirus disease 2019 (COVID-19). 
gent actions, such as a stern quarantine, meticulous contact tracing, and social distancing measures, were not employed effectively, which made US the epicenter of the pandemic. The authorities' lackadaisical approach, deeming it a seasonal flu despite medical intelligence and CDC warnings, provided further fuel for the situation to escalate $[9,10]$.

As depicted in Figure 2, a sharp contrast can be observed in the imposition of containment strategies between both countries. Korea's technological infrastructure enabled contact tracing, quarantine measures, and early and widespread testing, and its enforcement of the travel ban gave the Korean government the upper hand in halting the spread of COVID-19 without causing undue damage to major businesses. Arguably, Korea outpaced the US by invoking an early partial lockdown, strict enforcement of fortnight quarantine, barring gatherings, and closing educational institutions well before the country registered its first 1000 cases. Although the US implemented fortnight quarantine, it delayed other containment strategies.

The chronological graphs shown in Figures 1 and 2 reflect the value of timely decisions and forecasting and underscore the necessity of being firm and rigorous in enacting strategies to combat COVID-19. Furthermore, community participation is of the utmost importance in any catastrophe of this magnitude.

A limitation of the present article is that it did not address the factors associated with the incidence and mortality of COVID-19.

The key implication of this comparative analysis for all nations is that no country and no province is immune to this gargantuan pandemic. The discrepancy between the US and Korea provide an enormous opportunity to consider the profound implications of botching prompt preparation for a pandemic and failing to take action at the earliest possible time. Countermeasures and policies need to be decided rapidly, with the suitable rigor, and must be executed with commitment. Whatever the outcomes of the pandemic may be, COVID-19 reminds us that "it's not what we have, but how we act with what we have" that makes the difference.

\section{Ethics Statement}

This paper is a perspective, so it did not need ethical approval.

\section{CONFLICT OF INTEREST}

The authors have no conflicts of interest associated with the material presented in this paper.

\section{FUNDING}

None.

\section{ACKNOWLEDGEMENTS}

None.

\section{AUTHOR CONTRIBUTIONS}

Conceptualization: Al, SS. Data curation: JJ, RVR. Funding acquisition: None. Visualization: JJ. Writing - original draft: Al, SS, JJ, VVR, RVR. Writing - review \& editing: NK, MD.

\section{ORCID}

Alwin Issac https://orcid.org/0000-0002-4528-8787

Shine Stephen https://orcid.org/0000-0002-4875-2979

Jaison Jacob https://orcid.org/0000-0002-4783-5369

Vijay VR https://orcid.org/0000-0003-1728-5201

Rakesh Vadakkethil Radhakrishnan https://orcid.org/00000003-1274-2354

Nadiya Krishnan https://orcid.org/0000-0003-2667-9579

Manju Dhandapani https://orcid.org/0000-0003-3351-3841

\section{REFERENCES}

1. Worldometer. Coronavirus: COVID-19 coronavirus pandemic [cited 2020 Apr 28]. Available from: https://www.worldometers.info/coronavirus/?fbclid = IwARORYMPhu-J9i5t74sla8KOrJFIhGMs--OYluvQzoxLeFrvwwr5FLpn42Qw.

2. World Bank. Population density (people per sq. km of land area) - Korea, Rep., United States [cited 2020 Apr 29]. Available from: https://data.worldbank.org/indicator/EN.POP.DNST? locations $=$ KR-US.

3. United Nations Development Programme. Human development reports: 2019 Human Development Index ranking [cited 2020 Apr 30]. Available from: http://hdr.undp.org/en/content/ 2019-human-development-index-ranking.

4. Korea Centers for Disease Control \& Prevention. The updates on COVID-19 in Korea as of 16 April [cited 2020 May 20]. Available from: https://www.cdc.go.kr/board/board.es?mid =a3040200 0000\&bid $=0030 \&$ act $=$ view\&list $\_n o=366909 \&$ tag $=\&$ Page $=$ 1.\%20Press\%20release.

5. COVID-19 National Emergency Response Center, Epidemiolo- 
gy \& Case Management Team, Korea Centers for Disease Control \& Prevention. Contact transmission of COVID-19 in South Korea: novel investigation techniques for tracing contacts. Osong Public Health Res Perspect 2020;11(1):60-63.

6. Kwon KT, Ko JH, Shin H, Sung M, Kim JY. Drive-through screening center for COVID-19: a safe and efficient screening system against massive community outbreak. J Korean Med Sci 2020; 35(11):e123.

7. Farrer M. Coronavirus: South Korea cluster drives huge rise in cases. The Guardian; 2020 Feb 22 [cited 2020 Apr 28]. Available from: https://www.theguardian.com/world/2020/feb/22/coronavirus-south-korea-sees-huge-jump-cases-china-hubei-wuhan-outbreak-.

8. Wang J, Lindsay Huth L, Umlauf T. How the CDC's restrictive testing guidelines hid the coronavirus epidemic: U.S. health officials' slow response to the global spread led to a lag in testing. Wall Street Journal; 2020 Mar 22 [cited 2020 Apr 25]. Available from: https://www.wsj.com/articles/how-the-cdcsrestrictive-testing-guidelines-hid-the-coronavirus-epidemic-11584882001.

9. Jernigan DB; CDC COVID-19 Response Team. Update: public health response to the coronavirus disease 2019 outbreak United States, February 24, 2020. MMWR Morb Mortal Wkly Rep 2020;69(8):216-219.

10. Josh Margolin J, Meek JG. Intelligence report warned of coronavirus crisis as early as November: sources. ABC News; 2020 Apr 9 [cited 2020 Apr 23]. Available from: https://abcnews. go.com/Politics/intelligence-report-warned-coronavirus-crisis-early-novembr-sources/story? $\mathrm{id}=70031273$. 